\title{
Supporting Information for: Formation of Rod-Shaped Calcite Crystals by Microemulsion-Based Synthesis
}

\author{
Dongxia Liu and Matthew Z. Yates* \\ Department of Chemical Engineering and Laboratory for Laser Energetics, University of Rochester, \\ Rochester, NY, 14627 E-mail: myates@che.rochester.edu; Tel: 001-585-273-2335.
}

\section{Experimental}

Materials: Cyclohexane (99.9\% purity) was provided by Mallinckrodt Baker, Inc. The surfactant CTAB and ammonium carbonate were purchased from Aldrich and Sigma, respectively. The calcium chloride dihydrate and 1-propanol supplied by Sigma-Aldrich were all 99+\% (A.C. S. reagent). Distilled and deionized water was used.

Typical experimental procedure for synthesis of $\mathrm{CaCO}_{3}$ particles in microemulsions: The micellar solution containing 1g CTAB, $30 \mathrm{ml}$ cyclohexane, $1.5 \mathrm{ml} 1$-pentanol and $1.341 \mathrm{~g}$ $\mathrm{CaCl}_{2}(1.94 \mathrm{M})$ aqueous solution was prepared under mild magnetic stirring for $30 \mathrm{~min}$. $1.298 \mathrm{~g}$ aqueous $\left(\mathrm{NH}_{4}\right)_{2} \mathrm{CO}_{3}$ solution with the same molar concentration as that of $\mathrm{CaCl}_{2}$ was added to microemulsions and the reaction was continued for desired time at room temperature. The product was collected by centrifugation at $8000 \mathrm{rpm}$ and washed three times by dispersing the crystals in absolute ethanol then collecting the crystals by centrifugation. The wet product was dried in a vacuum oven at room temperature overnight. The materials and synthetic procedure for rhombohedral calcite crystals were the same as those of prismatic calcite formed in microemulsions except that the reagents were dissolved in pure aqueous phase without the existence of CTAB surfactant, co-surfactant 1pentanol and cyclohexane. 


\section{Analytical methods}

The crystal structure was determined by X-ray powder diffraction (Philips PW3020) with

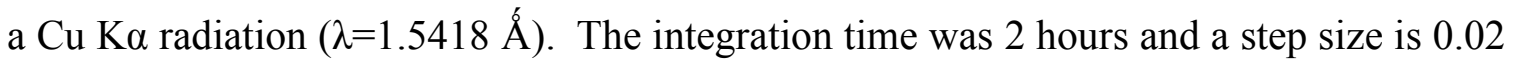
degree/3 second. The FT-IR spectrum was recorded with a spectrophotometer (FTIR8400 S Shimadzu) in the range of 500-4000 $\mathrm{cm}^{-1}$. Each sample was measured with 32 scans at an effective resolution of $2 \mathrm{~cm}^{-1}$. The morphology of the products was examined with SEM (LEO 982 FE-SEM) after coating with 80 to $100 \mathrm{~nm}$ of metal (Au 60\%, Pd 40\%). TEM images were recorded on a JEOL TEM 2000 EX microscope at an accelerating voltage of $200 \mathrm{KV}$. The TEM sample was prepared by placing a drop of a dispersed solution of particles in hexane onto a carbon-coated copper grid. After evaporation of solvent in fume hood, the samples were ready for use. The thermogravity analysis (TGA) was conducted using a TGA instrument (SDT-Q600), under an air flow of $100 \mathrm{ml}$ per min with a heating rate of $10^{\circ} \mathrm{C}$ per min from $30^{\circ} \mathrm{C}$ to $1000^{\circ} \mathrm{C}$. 
XRD spectra of rhombohedral calcite particles

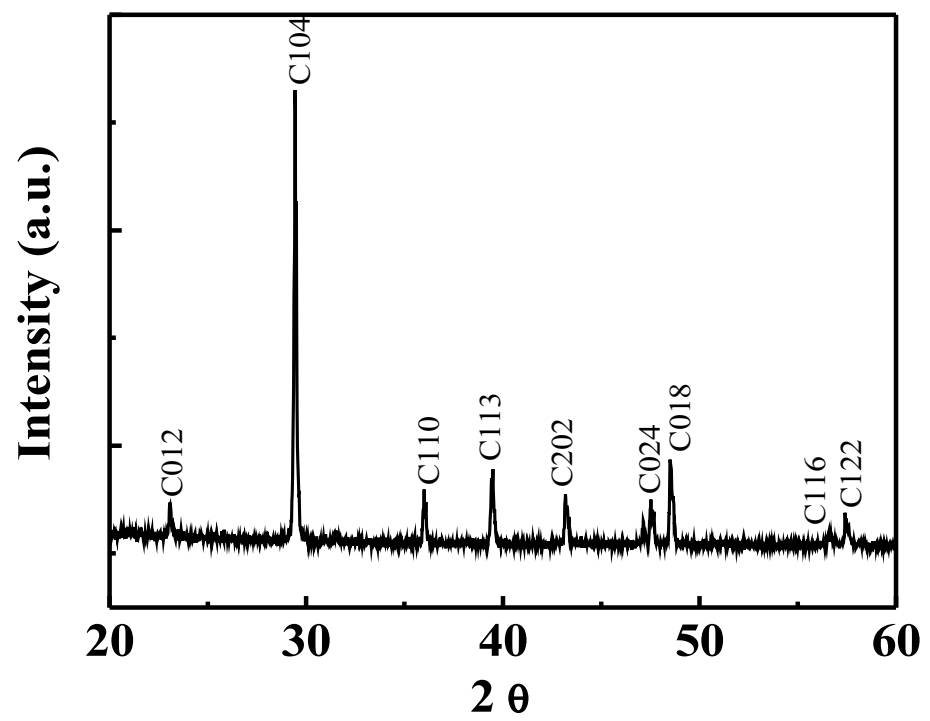

Fig. 1. XRD spectra of calcite particles prepared from the pure aqueous solutions without the presence of microemulsions. 
TGA analysis of CTAB, prismatic and rhombohedral calcite crystals

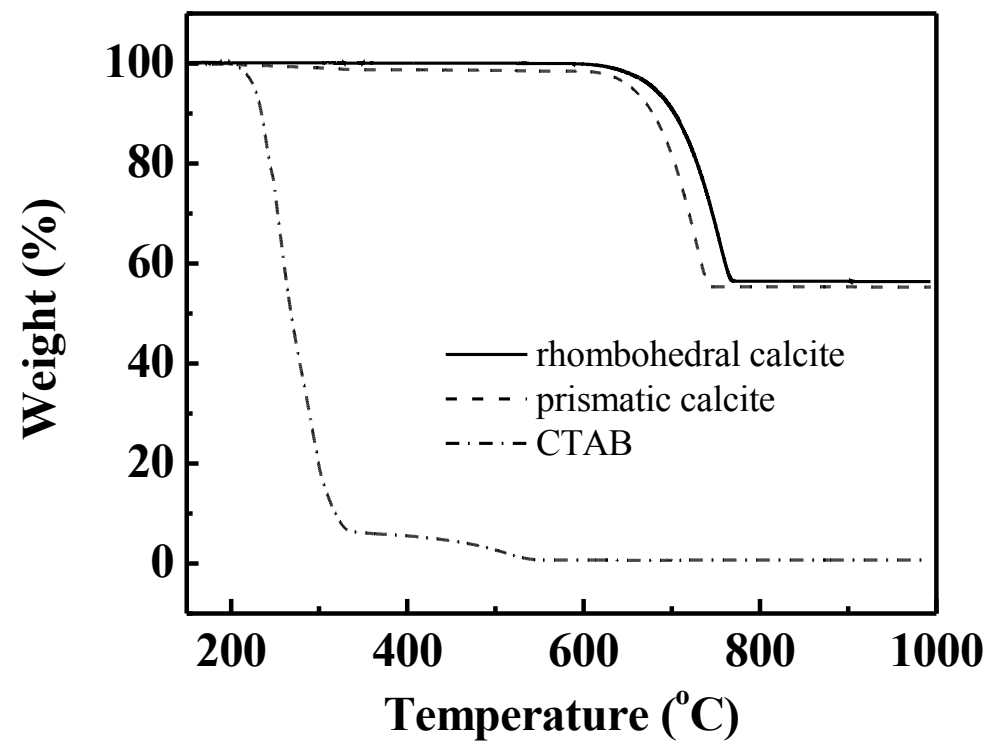

Fig. 2. TGA curves of CTAB surfactant and calcite crystals synthesized in pure aqueous solution and in CTAB w/o microemulsion, respectively. 